\title{
Grocery Stores Are Not Associated with More Healthful Food for Participants in the Supplemental Nutrition Assistance Program
}

\author{
Allison M. Lacko; Barry M. Popkin, PhD; Lindsey Smith Taillie, PhD
}

\author{
ARTICLE INFORMATION \\ Article history: \\ Submitted 17 January 2018 \\ Accepted 6 June 2018 \\ Available online 1 September 2018

\section{Keywords:} \\ At-home \\ Away-from-home \\ Diet quality \\ Low-income \\ Supplemental Nutrition Assistance Program
}

\begin{abstract}
Background Despite interventions to improve the nutrition of grocery store purchases, also referred to as at-home $(\mathrm{AH})$ foods, by participants in the Supplemental Nutrition Program (SNAP), little is known about what proportion of participants' intake is from AH foods and how the dietary quality of AH food compares with participants' away-from-home (AFH) food. Although recent research indicates SNAP participants have dietary quality that is slightly worse than that of income-eligible nonparticipants, it is unknown whether this is attributable to $\mathrm{AH}$ or $\mathrm{AFH}$ consumption.

Objective The objective of this study is to examine differences in self-reported dietary intake by food source for SNAP participants compared with income-eligible nonparticipants using 2011-2014 data from the National Health and Nutrition Examination Survey (NHANES).

Design This study included data from the NHANES, a cross-sectional, nationally representative survey of the United States population.

Study participants This study included 2,523 adults with low incomes ( $\leq 130 \%$ of the federal poverty level) in NHANES (2011-2014).

Main outcome measures Self-reported intake of calories, solid fats, added sugars, and servings of nonstarchy vegetables, whole fruits, and whole grains was assessed by food source in SNAP participants and income-eligible nonparticipants.

Statistical analysis Multivariate linear regression was used for each outcome, controlling for relevant sociodemographic characteristics. Data were stratified by food source, including grocery stores, sit-down restaurants, and fast food.

Results SNAP participants had a higher intake of solid fats and added sugar from $\mathrm{AH}$ foods than nonparticipants. Added sugar from $\mathrm{AH}$ food accounted for $15.3 \%$ of total calories consumed by SNAP participants, compared with $11.8 \%$ for nonparticipants $(P<0.001)$. SNAP participants consumed fewer calories from sit-down restaurants, but both groups consumed similar amounts of calories from fast food. Consumption of nonstarchy vegetables, whole fruits, and whole grains was low for both groups.

Conclusions SNAP participants had poorer diet quality from consumption of AH food than did nonparticipants. Future research should focus on interventions to improve the healthfulness of grocery store purchases as a mechanism to improve dietary quality of SNAP participants.

J Acad Nutr Diet. 2019;119(3):400-415.
\end{abstract}

$\mathrm{P}$ OOR DIET HAS BEEN ASSOCIATED WITH A HIGHER incidence of obesity and chronic disease, ${ }^{1}$ and there is evidence that Americans with lower incomes disproportionately experience obesity and nutrition-related health problems. ${ }^{1,2}$ As the largest federal food assistance program, ${ }^{3}$ the Supplemental Nutrition Assistance Program (SNAP) has the potential to improve the nutrition of Americans with lower incomes and subsequently reduce health disparities in this vulnerable population. Although research on the 
quality of SNAP participants' diets has yielded mixed results, ${ }^{4,5}$ both a recent systematic review and a US Department of Agriculture report show that SNAP participants tend to have less healthy diets as measured by the Healthy Eating Index., 7

One major unanswered question is whether SNAP dietary quality varies by where food is obtained. Specifically, few studies $^{8,9}$ evaluate the dietary quality of food obtained from away-from-home (AFH) sources, such as fast food and sitdown restaurants, and at-home $(\mathrm{AH})$ food sources, such as grocery stores, for SNAP participants. SNAP can only have a positive effect on the dietary quality of $\mathrm{AH}$ food because benefits can only be used at grocery stores. Although it is established that SNAP participants are less likely than nonparticipants to eat AFH food ${ }^{10-12}$ and that an increase in SNAP benefits increases money spent on $\mathrm{AH}$ food, ${ }^{10,13}$ more money spent on groceries may not result in more nutritious purchases if foods are chosen for shelf-life stability or convenience. ${ }^{14,15}$ Although those who consume more $\mathrm{AH}$ food tend to have healthier diets, ${ }^{16,17}$ it is unknown whether this is true among SNAP participants. Furthermore, it is important to assess dietary trends in the context of a rapidly changing food supply, ${ }^{5}$ evolving food preferences, updated dietary guidelines, and rising trends in consumption of AFH food. ${ }^{18}$

The objective of this study is to examine differences in selfreported dietary intake by food source for SNAP participants compared with income-eligible nonparticipants using data from the National Health and Nutrition Examination Survey (NHANES) obtained from 2011 to 2014.

\section{METHODS AND DATA}

\section{Study Design and Population}

The present analysis included 2,523 adults with lower incomes, ranging in age from 20 to 64 years, from the 20112012 and 2013-2014 waves of the NHANES. NHANES is a representative, cross-sectional study of the noninstitutionalized United States population with a stratified, four-stage probability sampling design. Oversampling is carried out for certain subgroups, including Hispanics, non-Hispanic blacks, and persons with lower income. Data collection includes demographic and health interviews, as well as 24-hour dietary recalls. ${ }^{19}$ This study was deemed exempt from institutional review board approval by the University of North Carolina Office of Human Research Ethics because it does not constitute human subjects research as defined under federal regulations [45 CFR 46.102 ( $d$ of f) and 21 CFR 56.102 (c)(e)(l)].

The study population was limited to individuals meeting the gross income eligibility requirement to qualify for SNAP, defined as a family income $\leq 130 \%$ of the federal poverty level (FPL). ${ }^{20}$ Sensitivity analyses were conducted by expanding the population to those at $200 \%$ of the FPL for two reasons. First, higher-income households can receive benefits based on broadened net income and asset testing, which increased SNAP enrollment after the 2008 recession. ${ }^{21}$ Second, because eligibility is transitory over the course of the year, particularly among adults in low-wage jobs, some families may have been eligible for SNAP at the time of the survey despite having an annual income higher than the 130\% FPL threshold. ${ }^{3,22-24}$ In the sensitivity analyses, only the association between SNAP participation and per-consumer consumption of calories from restaurants was affected and found to no longer be significant.

\section{RESEARCH SNAPSHOT}

Research Question: Does the association between Supplemental Nutrition Assistance Program (SNAP) participation and dietary quality differ by food source, including grocery stores, sit-down restaurants, and fast food?

Key Findings: In this cross-sectional study with 2,523 adults with low income ( $\leq 130 \%$ of the federal poverty level) in the National Health and Nutrition Examination Survey (20112014), SNAP participation was associated with higher selfreported consumption of solid fat and added sugar from grocery store foods. SNAP participants consumed fewer calories from sit-down restaurants than income-eligible nonparticipants, but both groups consumed similar amounts of calories from fast food. Consumption of nonstarchy vegetables, whole fruits, and whole grains was low for both groups.

\section{SNAP Exposure}

SNAP participants were identified using the NHANES Food Security Questionnaire, ${ }^{25}$ and individuals were considered SNAP beneficiaries if they reported receiving SNAP benefits in the past 30 days. Individuals with reported incomes $\leq 130 \%$ of the FPL but not currently receiving SNAP benefits were considered "income-eligible nonparticipants" (hereafter referred to as nonparticipants). Although it is common in the literature to define SNAP participation as receipt of benefits in the past 12 months, ${ }^{26,27}$ the present study includes the assumption that individuals would only alter their intake behavior while they were currently receiving SNAP benefits. When SNAP participation was instead defined as receipt of benefits within the past 12 months at $130 \%$ of the FPL, only the association of SNAP participation and the consumption of solid fats from grocery store foods were affected. Although the association was no longer significant, there was little substantive difference in amount of solid fats consumed. An additional sensitivity analysis defined SNAP participation as the receipt of benefits in the past 30 days, but nonparticipants only included those income-eligible individuals who had not used SNAP in the past 12 months. Individuals who used SNAP within the past 12 months but not the past 30 days were excluded from the study sample. ${ }^{28}$ This change did not affect associations between SNAP status and nutrient outcomes.

\section{Dietary Data}

Details of the NHANES method of collecting dietary intake data have been described elsewhere. ${ }^{29}$ Self-reported dietary data are collected via a 24-hour recall during an in-person interview using USDA's Automated Multiple Pass method. ${ }^{30}$ The analytic sample includes only the first day of 2 days of dietary intake data, as recommended for the examination of population means. ${ }^{31}$ Waves of NHANES were combined to ensure sufficient sample size (2011-2012 with 2013-2014). Caloric data were sourced from the USDA's Food and Nutrient Database for Dietary Studies ${ }^{32}$; whereas solid fats, added sugars, servings of fruit and vegetables, and ounce equivalents of whole grains were sourced from the USDA's Food 
Patterns Equivalents Database ${ }^{33}$ for the corresponding survey cycles.

Dietary outcomes included calories, solid fats, added sugars, servings of nonstarchy vegetables, servings of whole fruits, and ounce equivalents of whole grains. According to the 2015-2020 Dietary Guidelines for Americans, solid fats and added sugars (SoFAS) are the two macronutrients Americans should limit in their diets, ${ }^{34}$ whereas nonstarchy vegetables, whole fruits, and whole grains are recommended and represent the majority of MyPlate. ${ }^{1}$ Participants reported where each food and beverage consumed was obtained. These food sources were categorized as 1) grocery store (store, convenience store, and store with no additional information), 2) sit-down restaurant (restaurant with waiter/ waitress, restaurant with no additional information, bar/ tavern/lounge, and cafeteria not at school), 3) fast-food restaurant (restaurant fast food/pizza; street vendor; and sport, recreation, or entertainment facility), and 4) other sources (including soup kitchens, community food programs, Meals on Wheels, vending machines, common coffee pot, mail-order purchases, home garden or hunting, fundraiser sales, gifts, and other). Study participants missing source information for at least one food item were excluded from analysis $(\mathrm{n}=30)$.

\section{Covariate Data}

Covariate data were collected from the intervieweradministered Demographic, ${ }^{35,36}$ Food Security, ${ }^{25,37}$ and Occupation questionnaires. ${ }^{38,39}$ Multivariate regression included covariates for sex, age (continuous, including quadratic term), race/ethnicity (Mexican-American, nonHispanic white, non-Hispanic black [referent], other), marital status (married/living with partner or other), poverty income ratio (family income as a percentage of the FPL, continuous), employment (yes/no), education (less than high school [referent], high school/general education diploma [GED], some college, or college graduate or above), participation in the Special Supplemental Nutrition Program for Women, Infants and Children (WIC) (recipient in the past 12 months or not), whether the dietary recall was for food consumed on the weekend (defined as Friday, Saturday, or Sunday) and year (2011-2012 or 2013-2014). Complete case analysis was used (missing covariate data: $n=2$ ).

\section{Statistical Analysis}

In all analyses the NHANES dietary day 1 sample weights were used to derive nationally representative estimates. As a result of pooling data from 2011 to 2014, these weights were recalculated to account for the probability of being sampled over 4 years instead of $2 .^{40}$ Proportions testing and $t$ tests were used to compare the sociodemographic characteristics of SNAP participants and nonparticipants in the study sample.

Ordinary least-squares linear regression models controlling for covariates were used to examine the association between SNAP status and nutrient intake for each of the four food source categories. The use of ordinary least-squares models is in line with similar research examining the association between SNAP status and dietary quality..$^{9,22,27,41,42}$ For primary analysis, the average nutrient intake per food source was estimated across the pooled sample population. Because few individuals report consumption of food from all four food sources in one 24-hour dietary recall, a secondary perconsumer analysis was conducted in which the average nutrient and food intakes per source were estimated only among those who consumed at least one food item from that source. In the first per-capita analysis, SoFAS were calculated as a percentage of total energy intake across all food sources, whereas in the second per-consumer analysis, SoFAS were calculated as a percentage of total energy intake from a given food source. In both analyses, a Wald test for the interaction between SNAP participation and survey year was found to be statistically insignificant; therefore pooling data from 2011-2014 was not found to violate the assumption of homogeneity in the association between SNAP participation and nutrient intake within this period. In addition, a sensitivity analysis was conducted to evaluate whether results were robust to outliers. Exclusion of the top $1 \%$ of consumers of each dietary outcome did not alter significant associations.

Statistical analyses were performed using STATA 14.2. ${ }^{43}$ Estimates were generated using STATA's survey (svy) command to adjust for NHANES complex survey design. Variance estimates were calculated using Taylor Series Linearization methods as recommended by the National Center for Health Statistics. ${ }^{44}$ This method generates linear approximations for the nonlinear estimates resulting from NHANES' complex sampling design and uses the STATA vce(unconditional) option on estimation commands. Significant differences in nutrient intakes were identified with Wald tests using STATA margins and contrast postestimation commands to compare participant groups. All hypothesis testing was two sided with a significance level of $P<0.025$ to adjust for multiple comparisons.

\section{RESULTS}

\section{Means and Proportions, Unadjusted for Covariates}

Of the 2,523 adults included in the sample period, 1,191 (47.2\%) reported current participation in SNAP (Table 1). SNAP participants were more likely to be women, identify as nonHispanic black, and receive Special Supplemental Nutrition Program for Women, Infants and Children (WIC) benefits. Although the sample was restricted to individuals with a family income at or below $130 \%$ of the FPL, participants were still found to have a lower poverty income ratio than nonparticipants. Participants were also less likely to be employed or have a college degree.

SNAP participants reported consuming a greater percentage of daily total calories from food obtained from grocery stores than did nonparticipants (Table 2), which was true for average consumption of grocery store food (per capita, $P=0.01$ ), as well as when the sample was restricted to only those individuals who consumed any food from grocery stores (per consumer, $P=0.004$ ). On average, SNAP participants were less likely to eat at sit-down restaurants (per capita, $P=0.001$ ). SNAP participants also consumed a lower proportion of their total calories from food consumed at sitdown restaurants even when the sample was restricted to restaurant consumers (per consumer, $P=0.036$ ). In addition, the per-consumer sample sizes in Table 2 indicate the extent of self-reported nonconsumption by food source and by dietary outcome. 
Table 1. Sociodemographic and average dietary intake characteristics for SNAP ${ }^{\mathrm{a}}$-eligible adults, NHANES ${ }^{\mathrm{b}}$ 2011$2014^{c}$

\begin{tabular}{|c|c|c|}
\hline & SNAP & Non-SNAP \\
\hline $\mathrm{N}$ & 1,191 & 1,332 \\
\hline Missing data ${ }^{d}$ & 14 & 18 \\
\hline \multicolumn{3}{|l|}{ Sociodemographic data } \\
\hline Female (\%) & 56.5 & $50.3^{*}$ \\
\hline Age, mean $\pm \mathrm{SE}^{\mathrm{e}}$ & $39.1 \pm 0.6$ & $37.7 \pm 1.6$ \\
\hline Poverty Income Ratio, mean \pm SE & $0.66 \pm 0.02$ & $0.84 \pm 0.03^{* * *}$ \\
\hline Married/living with partner (\%) & 41.5 & 49.9 \\
\hline Employed (\%) & 40.2 & $57.0^{* * *}$ \\
\hline WIC recipient (\%) & 4.8 & $1.1^{* * *}$ \\
\hline \multicolumn{3}{|l|}{ Race/ethnicity } \\
\hline Mexican American (\%) & 12.9 & 17.5 \\
\hline Non-Hispanic white (\%) & 45.8 & 52.1 \\
\hline Non-Hispanic black (\%) & 24.7 & $12.7^{* * *}$ \\
\hline Other/Multiracial (\%) & 16.7 & 17.7 \\
\hline \multicolumn{3}{|l|}{ Education } \\
\hline Less than high school (\%) & 34.8 & $25.1^{*}$ \\
\hline High school/GED ${ }^{g}(\%)$ & 31.9 & $23.4^{*}$ \\
\hline Some college (\%) & 29.0 & $36.8^{*}$ \\
\hline College graduate or above (\%) & 4.3 & $14.7^{* * * *}$ \\
\hline \multicolumn{3}{|l|}{ Dietary data } \\
\hline Daily calories, mean $\pm \mathrm{SE}$ & $2,298 \pm 47$ & $2,276 \pm 57$ \\
\hline $\begin{array}{l}\% \text { 24-hour recalls conducted } \\
\text { on a weekend day, Fri-Sun }\end{array}$ & 41.3 & 38.7 \\
\hline
\end{tabular}

${ }^{\mathrm{a}} \mathrm{SNAP}=$ Supplemental Nutrition Assistance Program.

${ }^{\mathrm{b}} \mathrm{NHANES}=$ National Health and Nutrition Examination Survey.

cData are for adults aged $20-64$ years with an income at or below $130 \%$ of the federal poverty level from NHANES 2011-2012 and 2013-2014. The sample sizes represent complete case analysis. Data are weighted and nationally representative but are not adjusted.

${ }^{d}$ Number of individuals excluded from Table 1 statistics and statistical analysis either due to missing covariate data or missing food source information for at least one caloriecontaining food item.

e $\mathrm{SE}=$ standard error.

${ }^{f}$ WIC $=$ Special Supplemental Nutrition Program for Women, Infants, and Children.

${ }^{9} \mathrm{GED}=$ general education diploma.

*Means/proportions are different between SNAP participants and nonparticipants at $P<0.05$.

*** $P<0.001$.

\section{Adjusted Regression Estimates}

SNAP participants and nonparticipants consumed similar total calories, a similar proportion of total calories from solid fat, and similar ounce equivalents of whole grains (Table 3 ). Compared with nonparticipants, however, SNAP participants consumed a higher proportion of total calories from added sugar (2.7 percentage points greater, $P=0.001$ ), 0.3 fewer servings of nonstarchy vegetables $(P<0.001)$, and 0.2 fewer servings of whole fruit $(P<0.001)$.
Important patterns emerged when average nutrient intake by food source was assessed. SNAP participants consumed 181 more calories from grocery store foods than nonparticipants $(P=0.004)$, despite consuming similar total calories. Consistent with this pattern, SNAP participants consumed more of their daily calories as solid fats and added sugars (SoFAS) derived from grocery store foods compared with nonparticipants (1.0 percentage point higher for solid fats, $P=0.018$; 3.5 percentage points higher for added sugar, $P<0.001$ ). Additional exploratory analysis suggests that this difference in added sugar consumption may be driven by beverage consumption, as shown in Table 4. Patterns in intake also differed according to the source of AFH food. Both groups consumed similar amounts of calories from food obtained from fast-food restaurants. However, SNAP participants, on average, consumed 151 fewer calories from food consumed at sit-down restaurants than nonparticipants $(P<0.001)$.

The consumption of healthy foods, including nonstarchy vegetables, whole fruits, and whole grains, was low for both groups. SNAP participants consumed 0.2 fewer servings of nonstarchy vegetables from grocery store foods $(P=0.004)$. Despite this, for both SNAP participants and nonparticipants, the highest proportion of servings of healthy food came from grocery stores.

Table 3 also presents data on nutrient intakes for individuals who reported consuming food from a particular food source. SNAP participants who obtained food from grocery stores consumed more added sugar as a percentage of their total calories from grocery store foods than nonparticipants ( 3.2 percentage points higher, $P=0.003$ ) (Figure). In other words, for SNAP participants, $22.7 \%$ of calories from grocery store foods were derived from added sugar compared with $19.5 \%$ of calories for nonparticipants.

In addition, although the average amount of per-capita calories from sit-down and fast-food restaurants was low, these sources are substantial sources of calories for those who consume them. For example, the per-capita average consumption of fast food by SNAP participants was 354 calories, whereas the per-consumer average was 997 calories. Among fast-food consumers, no difference was found in calories, SoFAS, or healthy food intake between SNAP participants and nonparticipants. However, in both participant groups, the percentage of calories from fast food attributable to solid fats is notably higher than the percentage of calories from grocery store foods derived from solid fats. In comparison with fast food, there is a significant association between SNAP status and calories from sitdown restaurants. In other words, even when only consumers of food at sit-down restaurants are considered, SNAP participants consume fewer calories than nonparticipants. However, this association is no longer significant in a sensitivity analysis increasing the income of the study sample to $200 \%$ of the FPL from $130 \%$ of the FPL because of the decrease in mean consumption by nonparticipants as shown in Table 5.

Although not the primary focus of this study, these associations between SNAP status and nutrient intakes are found to be robust when cross-sections from 2003 to 2006 and 2007 to 2010 are compared as shown in Table 6. Although there is no statistically significant association between SNAP status and SoFAS from grocery stores in the years 2003 to 2006, possibly because of the small sample of SNAP 
Table 2. Per-capita and per-consumer average dietary intake characteristics, by SNAP participation status (mean $\left.\pm \mathrm{SE}^{\mathrm{b}}\right)^{\mathrm{c}}$

$\begin{array}{llll}\text { Per-capita }^{d} \text { mean } & n & \% n^{e} & \text { Per-consumer }^{f} \text { mean }\end{array}$

Percentage of total daily energy intake derived from each food source

\section{SNAP participants}

Grocery store

Sit-down restaurant

Fast-food restaurant

Other source

\section{SNAP nonparticipants}

Grocery store

Sit-down restaurant

Fast-food restaurant

Other source

Daily consumption of nutrients and foods

\section{SNAP participants}

$\%$ Total energy from solid fats

$\%$ Total energy from added sugars

Servings of nonstarchy vegetables

Servings of whole fruits

Ounce equivalents of whole grains

SNAP nonparticipants

$\%$ Total energy from solid fats

$\%$ Total energy from added sugars

Servings of non-starchy vegetables

Servings of whole fruits

Ounce equivalents of whole grains

$$
\begin{array}{r}
72.5 \pm 1.5 \\
4.0 \pm 0.6 \\
16.0 \pm 1.2 \\
7.6 \pm 0.8
\end{array}
$$

$65.4 \pm 2.9^{*}$
$10.5 \pm 1.7^{* *}$
$16.1 \pm 1.2$
$7.9 \pm 0.6$

$14.9 \pm 0.5$

$17.8 \pm 0.8$

$0.8 \pm 0.04$

$0.4 \pm 0.04$

$0.6 \pm 0.04$

$14.7 \pm 0.3$
$14.9 \pm 0.5^{* *}$
$1.1 \pm 0.04^{* * *}$
$0.6 \pm 0.03^{* * *}$
$0.7 \pm 0.05$

$14.7 \pm 0.3$

1,317

1,305

1,202

667

589

97.6

13.0

39.7

28.7

98.0

20.9

42.8

34.8

1,171

1,174

998

450

482

$0.7 \pm 0.05$

98.3

98.6

83.8

37.8

40.5

$15.1 \pm 0.3$

$18.0 \pm 0.8$

$0.9 \pm 0.03$

$1.1 \pm 0.07$

$1.5 \pm 0.08$

${ }^{a}$ SNAP $=$ Supplemental Nutrition Assistance Program.

${ }^{\mathrm{b}} \mathrm{SE}=$ standard error.

'Results are corrected for National Health and Nutrition Examination Survey (NHANES) complex survey design but are proportions and are unadjusted.

der-capita mean consumption is calculated using the full sample of 1,191 SNAP participants and 1,332 nonparticipants as the denominator for the average.

eProportion of participants who were consumers. For food source data, food source consumers are defined as those individuals who consumed at least one food item from the food source

For nutrient and food data, consumers are defined as having a nonzero consumption for a given nutrient or food group.

${ }^{f}$ Per-consumer mean consumption is calculated using only consumers as the denominator for the average, which is equal to the sample population $n$ in the corresponding row.

*Significant difference between SNAP participants and nonparticipants, $P<0.05$.

${ }^{*} P<0.01$.

*** $P<0.001$.

participants during this period $(\mathrm{n}=373$ ), a substantive difference is still noted.

\section{DISCUSSION}

Few studies have analyzed the relationship between SNAP status and dietary quality relative to where food is obtained. $^{8,9}$ Although SNAP participants consume a greater proportion of total calories from grocery store foods (Table 2), this does not translate to an improvement in dietary quality. The present study confirms previous findings that SNAP participants have slightly unhealthier diets compared with those of income-eligible nonparticipants. ${ }^{4,8,22,28}$ In particular, this difference in dietary quality appears to be primarily from foods consumed from grocery stores: SNAP participants consume more SoFAS and fewer nonstarchy vegetables from grocery stores than nonparticipants.

The results of the present study also align with previous findings that most added sugar in the US diet is consumed from $\mathrm{AH}$ vs $\mathrm{AFH}$ foods ${ }^{45}$ and adds that SNAP participants consume a greater proportion of calories from added sugar than nonparticipants. The association between SNAP status and added sugar is robust across several analyses. First, SNAP participants consumed more added sugar from all food sources as a proportion of total calories compared with nonparticipants. Second, participants consumed more added sugar as a proportion of calories from grocery store foods compared with nonparticipants. Almost one quarter of all 
Table 3. Daily consumption according to source where food was purchased, by SNAP ${ }^{a}$ participation, NHANES ${ }^{\text {bc }}$

\begin{tabular}{|c|c|c|c|c|c|c|c|c|c|}
\hline \multirow[b]{2}{*}{ Food source } & \multicolumn{4}{|c|}{ Per Capita } & \multicolumn{4}{|c|}{ Per Consumer ${ }^{d}$} & \multirow[b]{2}{*}{$\begin{array}{l}\text { Total } \\
\text { consumption }\end{array}$} \\
\hline & $\begin{array}{l}\text { Grocery } \\
\text { store }\end{array}$ & $\begin{array}{l}\text { Sit-down } \\
\text { restaurant }\end{array}$ & $\begin{array}{l}\text { Fast } \\
\text { food }\end{array}$ & $\begin{array}{l}\text { Other } \\
\text { source }\end{array}$ & $\begin{array}{l}\text { Grocery } \\
\text { store }\end{array}$ & $\begin{array}{l}\text { Sit-down } \\
\text { restaurant }\end{array}$ & $\begin{array}{l}\text { Fast } \\
\text { food }\end{array}$ & $\begin{array}{l}\text { Other } \\
\text { source }\end{array}$ & \\
\hline \multicolumn{5}{|l|}{ Calories } & \multicolumn{5}{|l|}{ Calories } \\
\hline SNAP participants & $1,762 \pm 62$ & $65 \pm 19$ & $354 \pm 33$ & $183 \pm 26^{f}$ & $1,790 \pm 61$ & $828 \pm 62$ & $997 \pm 59$ & $592 \pm 53$ & $2,363 \pm 55$ \\
\hline Nonparticipants & $1,581^{e} \pm 48$ & $216^{\mathrm{e}} \pm 32$ & $371 \pm 32$ & $184 \pm 19$ & $1,599^{\mathrm{e}} \pm 46$ & $1,029^{e} \pm 80$ & $1,003 \pm 54$ & $520 \pm 40$ & $2,352 \pm 40$ \\
\hline \multicolumn{5}{|c|}{ Solid fats (\% total energy intake) $)^{g}$} & \multicolumn{5}{|c|}{ Solid fats (\% food source energy intake) $)^{g}$} \\
\hline SNAP participants & $10.1 \pm 0.3$ & $0.5 \pm 0.1$ & $2.8 \pm 0.3$ & $1.3 \pm 0.2$ & $13.5 \pm 0.3$ & $14.5 \pm 1.1^{9}$ & $19.1 \pm 1.3$ & $14.9 \pm 1.2$ & $14.9 \pm 0.4$ \\
\hline Nonparticipants & $9.1^{\mathrm{e}} \pm 0.4$ & $1.3^{\mathrm{e}} \pm 0.2$ & $3.0 \pm 0.2$ & $1.3 \pm 0.2$ & $12.9 \pm 0.5$ & $13.8 \pm 0.9$ & $20.2 \pm 1.0$ & $14.1 \pm 1.1$ & $14.7 \pm 0.4$ \\
\hline \multicolumn{5}{|c|}{ Added sugars ( $\%$ total energy intake) } & \multicolumn{5}{|c|}{ Added sugars ( $\%$ food source energy intake) } \\
\hline SNAP participants & $15.3 \pm 0.7$ & $0.3 \pm 0.1$ & $1.8 \pm 0.2$ & $1.4 \pm 0.2$ & $22.7 \pm 0.7$ & $13.9 \pm 1.3$ & $11.6 \pm 0.8$ & $22.6 \pm 2.6$ & $18.8 \pm 0.7$ \\
\hline Nonparticipants & $11.8^{\mathrm{e}} \pm 0.6$ & $1.0 \pm 0.2$ & $1.8 \pm 0.2$ & $1.4 \pm 0.2$ & $19.5^{\mathrm{e}} \pm 0.6$ & $12.4 \pm 1.6$ & $13.3 \pm 1.1$ & $21.7 \pm 2.4$ & $16.1^{\mathrm{e}} \pm 0.7$ \\
\hline \multicolumn{5}{|c|}{ Nonstarchy vegetables (servings) } & \multicolumn{5}{|c|}{ Nonstarchy vegetables (servings) } \\
\hline SNAP participants & $0.5 \pm 0.0$ & $0.0 \pm 0.0$ & $0.1 \pm 0.0$ & $0.1 \pm 0.0$ & $0.6 \pm 0.0$ & $0.4 \pm 0.1$ & $0.4 \pm 0.0$ & $0.2 \pm 0.0$ & $0.8 \pm 0.0$ \\
\hline Nonparticipants & $0.7^{\mathrm{e}} \pm 0.0$ & $0.1^{\mathrm{e}} \pm 0.0$ & $0.2 \pm 0.0$ & $0.1 \pm 0.0$ & $0.7^{\mathrm{e}} \pm 0.0$ & $0.6^{\mathrm{e}} \pm 0.1$ & $0.4 \pm 0.0$ & $0.2 \pm 0.0$ & $1.1^{\mathrm{e}} \pm 0.1$ \\
\hline \multicolumn{5}{|c|}{ Whole fruits (servings) } & \multicolumn{5}{|c|}{ Whole fruits (servings) } \\
\hline SNAP participants & $0.3 \pm 0.0$ & $0.0 \pm 0.0$ & $0.0 \pm 0.0$ & $0.0 \pm 0.0$ & $0.3 \pm 0.0$ & $0.0 \pm 0.0$ & $0.0 \pm 0.0$ & $0.1 \pm 0.0$ & $0.3 \pm 0.0$ \\
\hline Nonparticipants & $0.5 \pm 0.0$ & $0.0 \pm 0.0$ & $0.0 \pm 0.0$ & $0.1 \pm 0.0$ & $0.5 \pm 0.0$ & $0.1 \pm 0.0$ & $0.0 \pm 0.0$ & $0.2 \pm 0.0$ & $0.5^{\mathrm{e}} \pm 0.0$ \\
\hline \multicolumn{5}{|c|}{ Whole grains (ounce equivalents) } & \multicolumn{5}{|c|}{ Whole grains (ounce equivalents) } \\
\hline SNAP participants & $0.5 \pm 0.0$ & $0.0 \pm 0.0$ & $0.0 \pm 0.0$ & $0.0 \pm 0.0$ & $0.6 \pm 0.0$ & $0.1 \pm 0.0$ & $0.1 \pm 0.0$ & $0.1 \pm 0.1$ & $0.6 \pm 0.1$ \\
\hline Nonparticipants & $0.6 \pm 0.1$ & $0.0 \pm 0.0$ & $0.0 \pm 0.0$ & $0.0 \pm 0.0$ & $0.6 \pm 0.1$ & $0.1 \pm 0.0$ & $0.1 \pm 0.0$ & $0.2 \pm 0.1$ & $0.7 \pm 0.1$ \\
\hline
\end{tabular}

aSAP=Supplemental Nutrition Assistance Program.

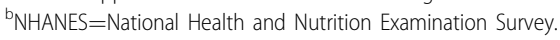

'Data are for adults aged 20 to 64 years with an income at or below 130\% of the federal poverty level from NHANES 2011-2012 and 2013-2014. The sample size for SNAP participants, defined as receipt of benefits in the past 30 days, was 1,191 and 1,332 for income-eligible nonparticipants. Data are nationally representative, and results account for complex survey design. Each nutrient outcome was calculated for each category of food source and included in a separate linear regression model. All models were adjusted for year, age (age and age ${ }^{2}$ ), sex, marital status, employment, race/ethnicity (Mexican American, non-Hispanic white, non-Hispanic black [referent], other), income (poverty income ratio), education (< high school [referent], high school, some college, or college graduate or above), weekend consumption and participation in the Special Supplemental Nutrition Program for Women, Infants and Children (WIC).

In addition to restricting the sample to SNAP-eligible adults aged 20 to 64 years with complete covariate and diet data, subpopulations are further restricted to those people who consumed calories from a given source. Therefore, the subpopulation for "Grocery store" only includes those people who purchased at least one food item from a grocery store ( $n=1,162$ for SNAP participants) and is different from the subpopulation for "Restaurant" ( $\mathrm{n}=155$ for SNAP participants), although there is overlap between the two. For percent intakes, the calories from saturated fat and added sugar (SoFAS) are divided by the total number of calories consumed from that source to calculate the percentage of calories from a given source that are attributable to SoFAS. Source-specific sample sizes are as follows: among SNAP participants, there were 1,162 grocery store consumers, 155 sit-down restaurant consumers, 473 fast-food restaurant consumers, and 342 other food source consumers; among nonparticipants, there were 1,304 grocery store consumers, 279 sit-down restaurant consumers, 570 fast-food consumers, and 463 other food source consumers.

ésignificant difference between SNAP participants and income-eligible nonparticipants within the same period, significant at $P<0.025$. These results are also bolded.

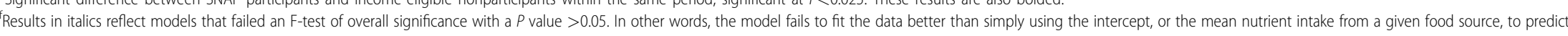
individual outcomes.

${ }^{9}$ Dietary data for solid fats, added sugars, servings, and ounce equivalents are from US Department of Agriculture Food Patterns Equivalents Database 2011-2012 and 2013-2014. Nonstarchy vegetables include dark green and orange vegetables, tomatoes, and other vegetables and exclude starchy vegetables, potatoes, and dry beans and peas. Added sugars are those used as ingredients in processed and prepared foods and do not include naturally occurring sugars. Discretionary solid fats include fats from animal sources or hydrogenated vegetable oils. 
Table 4. Per-capita daily consumption of calories and added sugar of select food groups obtained from grocery stores, NHANES $2011-2014^{\mathrm{b}}\left(\right.$ mean $\left.\pm \mathrm{SD}^{\mathrm{c}}\right)$

\begin{tabular}{|c|c|c|c|c|c|c|}
\hline \multirow[b]{2}{*}{ Food group ${ }^{g}$} & \multicolumn{2}{|c|}{ Calories $^{d}$} & \multicolumn{2}{|c|}{ Added Sugar, $\mathrm{g}^{\mathrm{e}}$} & \multicolumn{2}{|c|}{$\begin{array}{l}\text { Added Sugar, \% Total Energy } \\
\text { Intake }^{f} \\
\end{array}$} \\
\hline & $\begin{array}{l}\text { SNAP }^{\mathrm{h}} \\
\text { participants }\end{array}$ & Nonparticipants & $\begin{array}{l}\text { SNAP } \\
\text { participants }\end{array}$ & Nonparticipants & $\begin{array}{l}\text { SNAP } \\
\text { participants }\end{array}$ & Nonparticipants \\
\hline Meat & $54 \pm 6$ & $42 \pm 6$ & & & & \\
\hline Poultry & $63 \pm 7$ & $46 \pm 6$ & & & & \\
\hline $\begin{array}{l}\text { Processed meats, poultry } \\
\& \text { products }\end{array}$ & $51 \pm 5$ & $37 \pm 4$ & & & & \\
\hline Eggs \& egg dishes & $46 \pm 5$ & $26 \pm 3$ & & & & \\
\hline $\begin{array}{l}\text { Nuts, nut butters, seeds \& } \\
\text { coconut }\end{array}$ & $25 \pm 5$ & $37 \pm 6$ & & & & \\
\hline Breads, rolls, and tortillas & $118 \pm 8$ & $106 \pm 9$ & & & & \\
\hline $\begin{array}{l}\text { Fruits-fresh, frozen, } \\
\text { canned, or dried }\end{array}$ & $29 \pm 3$ & $44 \pm 3$ & & & & \\
\hline $\begin{array}{l}\text { Fried starchy vegetables } \\
\text { or starchy vegetable } \\
\text { dishes }\end{array}$ & $22 \pm 8$ & $10 \pm 2$ & & & & \\
\hline Grain-based desserts & $119 \pm 10$ & $108 \pm 12$ & & & & \\
\hline $\begin{array}{l}\text { Sweeteners, syrups, } \\
\text { jellies, and toppings }\end{array}$ & & & $6.2 \pm 0.5$ & $4.0 \pm 0.3$ & $1.9 \pm 0.4$ & $1.2 \pm 0.1$ \\
\hline Salty snacks & $89 \pm 8$ & $69 \pm 6$ & & & & \\
\hline Pasta \& pasta dishes & $76 \pm 19$ & $53 \pm 7$ & & & & \\
\hline Pizza \& calzone & $19 \pm 5$ & $34 \pm 7$ & & & & \\
\hline Coffee/tea & $52 \pm 10$ & $29 \pm 4$ & $10.5 \pm 2.5$ & $4.7 \pm 0.9$ & $2.3 \pm 0.4$ & $1.2 \pm 0.2$ \\
\hline $\begin{array}{l}\text { Sugar-sweetened } \\
\text { beverages }\end{array}$ & $154 \pm 11$ & $103 \pm 7$ & $36.6 \pm 2.6$ & $24.0 \pm 1.6$ & $9.7 \pm 0.7$ & $7.5 \pm 0.6$ \\
\hline Fluid milk & $79 \pm 9$ & $48 \pm 5$ & & & & \\
\hline Beer & $65 \pm 9$ & $51 \pm 10$ & & & & \\
\hline \multicolumn{7}{|c|}{ 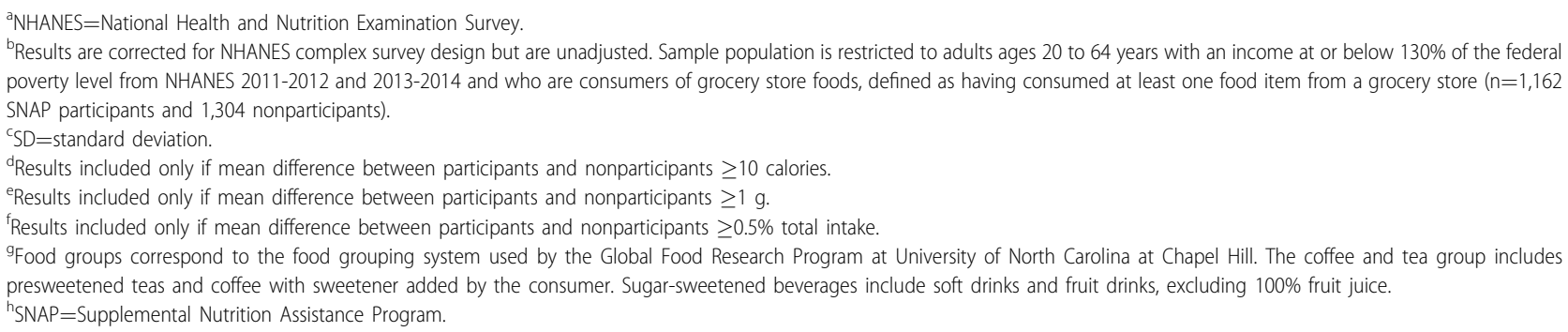 } \\
\hline
\end{tabular}

calories consumed by participants from grocery store foods came from added sugar alone (see Table 3). Recent studies that included purchase data have also demonstrated that SNAP participants buy more foods with added sugar compared with nonparticipants. ${ }^{7,46}$ The use of 24-hour recall data confirms that average consumption patterns reflect purchasing decisions among adults.

One possible explanation for the observed associations is that SNAP participation is an indicator of underlying food preference. SNAP participants may prefer foods with more added sugars than nonparticipants. In particular, several recent studies have indicated that SNAP participation is associated with sugar-sweetened beverage consumption. $9,24,41,47,48$ Food preference may be partly explained by biopsychological effects of stress that result in unhealthy food choices, ${ }^{49}$ and the present study confirms that SNAP participants are more likely to have lower incomes than nonparticipants (Table 1). Alternatively, greater consumption of added sugar and lower consumption of nonstarchy vegetables may be explained by food access and store preference. For example, SNAP participants are more likely to shop at supercenters if these stores are in their neighborhood. ${ }^{15,50}$ 


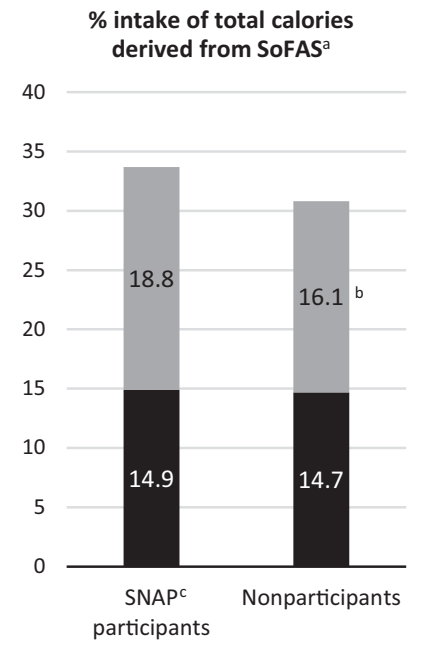

intake of total calorie
$\%$ of food source calories derived from SoFAS

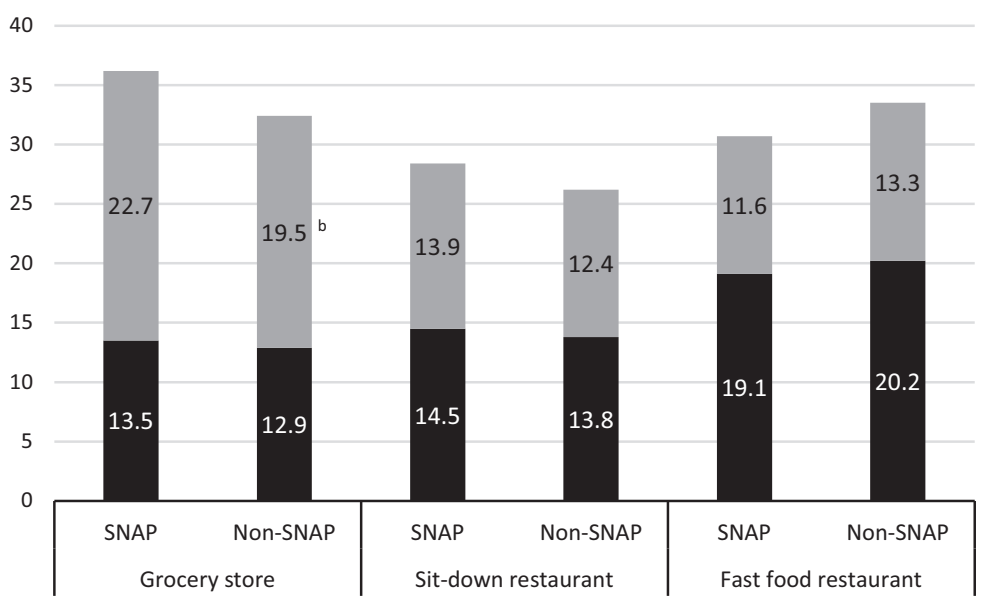

— intake from solid fat $\quad \%$ intake from added sugar

Figure. Proportion of food source calories attributable to SoFAS by SNAP participation. Data are for adults aged 20 to 64 years with an income at or below $130 \%$ of the federal poverty level from the National Health and Nutrition Examination Survey (NHANES) 2011-2012 and 2013-2014. The sample size for SNAP participants, defined as receipt of benefits in past 30 days, was 1,191 and 1,332 for income-eligible nonparticipants. Each nutrient outcome was calculated for each category of food source and included in a separate linear regression model. All models account for complex survey design and were adjusted for year, age (age, age2), sex, marital status, employment, race-ethnicity (Mexican American, non-Hispanic white, non-Hispanic black [ref], other), income (poverty income ratio), education (<high school [ref], high school, some college or college graduate or above), weekend consumption and participation in the Special Supplemental Nutrition Program for Women, Infants and Children (WIC). In order to calculate the percentage of calories from a given source that are attributable to SoFAS, the calories from saturated fat or added sugar were divided by the total number of calories consumed from that source. Dietary data for solid fats and added sugars are from USDA Food Patterns Equivalents Database (FPED) 2011-2012 and 2013-2014. Added sugars are those used as ingredients in processed and prepared foods and do not include naturally occurring sugars. Discretionary solid fats include fats from animal sources or hydrogenated vegetable oils. ${ }^{\mathrm{a}} \mathrm{SoFAS}=$ solid fats and added sugars. ${ }^{\mathrm{b}}$ Significant difference between SNAP participants and incomeeligible nonparticipants at $P<0.025$. 'SNAP=Supplemental Nutrition Assistance Program.

SNAP participants who shop at supercenters are more likely to purchase more of every food, including sugar-sweetened beverages and high-calorie items. ${ }^{15}$

Despite the relative healthfulness of $\mathrm{AH}$ food, ${ }^{51}$ these results indicate that it is not sufficient to improve nutrition in adults participating in SNAP solely by means of an increase in consumption of AH food. Food consumed from grocery stores and convenience stores makes up almost $73 \%$ of total intake for participants, which is significantly more than the $65 \%$ of intake for nonparticipants (Table 2). There is evidence that SNAP participants would prefer restrictions on eligible foods and/or incentives that encourage healthier diets. ${ }^{52-54}$ To take advantage of these preferences, successful nutrition education programs, such as SNAP-Ed, ${ }^{55}$ could be expanded. In addition, SNAP participants could be "nudged" to follow their preferences for a healthier diet using strategies from behavioral economics. ${ }^{14,56}$ For example, authorized SNAP retailers could be required to follow choice architecture guidelines that increase the display of healthy food in prominent locations while reducing shelf space for foods and beverages high in added sugar. ${ }^{14}$

Modifying SNAP-eligible foods using a combination of incentives and restrictions could also improve the dietary quality of $\mathrm{AH}$ foods. ${ }^{1,57,58}$ For example, results from the Healthy Incentives Pilot indicate that providing a rebate of 30 cents for every dollar spent on fruits and vegetables significantly increases the daily consumption of fruits and vegetables. Participants receiving the rebate did not use their increase in SNAP benefits to consume more unhealthy foods. ${ }^{59}$ Recent research estimates that fruit and vegetable incentive programs, including the Healthy Incentives Pilot, are cost effective because of the improved quality of life of SNAP participants ${ }^{60}$ and reduced societal cost of chronic disease. $^{61}$ In addition, recent research indicates that restricting the eligibility of specific unhealthy foods would decrease the consumption of SoFAS. ${ }^{62-64}$ Supplementary analysis in the present study showed that the difference in added sugar consumption from AH food may be driven by the consumption of sugar-sweetened beverages (see Table 4), including sweetened coffee and tea, sodas, and fruit drinks. Further research is needed to establish which food groups are the primary drivers of the difference in SoFAS consumption between participants and nonparticipants and therefore the most appropriate targets for purchase restrictions.

Although research shows that SNAP participants spend less on AFH foods compared with income-eligible nonparticipants, ${ }^{65}$ the results of the present study indicate that participants consume a lower proportion of AFH food specifically because they eat out less frequently at sit-down restaurants. In comparison, both groups consume a similar amount of calories from fast food (Table 3), which is associated with poor diet quality and health outcomes. ${ }^{17,66}$ These 
Table 5. Sensitivity analysis of daily nutrient consumption according to category of where food was purchased, by SNAP ${ }^{\mathrm{a}}$ participation, NHANES ${ }^{\mathrm{b}}$ 2011-2014

\begin{tabular}{|c|c|c|c|c|c|c|c|c|c|}
\hline \multirow[b]{2}{*}{ Food source } & \multicolumn{4}{|c|}{ Per-Capita Nutrient Consumption } & \multicolumn{4}{|c|}{ Per-Consumer Nutrient Consumption ${ }^{d}$} & \multirow[b]{2}{*}{$\begin{array}{l}\text { Total } \\
\text { consumption }\end{array}$} \\
\hline & Grocery store & $\begin{array}{l}\text { Sit-down } \\
\text { restaurant }\end{array}$ & Fast food & Other source & Grocery store & $\begin{array}{l}\text { Sit-down } \\
\text { restaurant }\end{array}$ & Fast food & Other source & \\
\hline
\end{tabular}

\section{Calories}

SNAP participants in last 30 days

\begin{tabular}{|c|c|c|c|c|c|c|c|c|c|}
\hline$\leq 130 \% \mathrm{FPL}^{\mathrm{e}}$ & $1,762 \pm 62^{f}$ & $65 \pm 19$ & $354 \pm 33$ & $183 \pm 26$ & $1,790 \pm 61$ & $828 \pm 62$ & $997 \pm 59$ & $592 \pm 53$ & $2,363 \pm 55$ \\
\hline$\leq 200 \% \mathrm{FPL}$ & $1,728 \pm 55$ & $77 \pm 17$ & $382 \pm 29$ & $179 \pm 26$ & $1,752 \pm 55$ & $818 \pm 55$ & $983 \pm 56$ & $583 \pm 52$ & $2,366 \pm 53$ \\
\hline \multicolumn{10}{|c|}{ NAP participants in last 12 months } \\
\hline$\leq 130 \% \mathrm{FPL}$ & $1,755 \pm 60$ & $70 \pm 17$ & $362 \pm 32$ & $180 \pm 23$ & $1,781 \pm 60$ & $823 \pm 56$ & $1,003 \pm 56$ & $586 \pm 48$ & $2,367 \pm 59$ \\
\hline$\leq 200 \% \mathrm{FPL}$ & $1,706 \pm 56$ & $91 \pm 18$ & $387 \pm 28$ & $179 \pm 24$ & $1,729 \pm 55$ & $803 \pm 55$ & $981 \pm 54$ & $587 \pm 47$ & $2,363 \pm 58$ \\
\hline
\end{tabular}

SNAP participants in last 30 days, excluding occasional

participants $^{9}$

\begin{tabular}{|c|c|c|c|c|c|c|c|c|c|}
\hline$\leq 130 \% \mathrm{FPL}$ & $1,751 \pm 62$ & $68 \pm 19$ & $350 \pm 36$ & $188 \pm 26$ & $1,779 \pm 62$ & $840 \pm 60$ & $991 \pm 62$ & $606 \pm 55$ & $2,356 \pm 56$ \\
\hline$\leq 200 \% \mathrm{FPL}$ & $1,722 \pm 54$ & $78 \pm 17$ & $377 \pm 31$ & $185 \pm 26$ & $1,746 \pm 54$ & $817 \pm 57$ & $978 \pm 56$ & $598 \pm 52$ & $2,362 \pm 52$ \\
\hline \multicolumn{10}{|c|}{ Vonparticipants in last 30 days } \\
\hline$\leq 130 \% \mathrm{FPL}$ & $1,581^{h} \pm 48$ & $216^{h} \pm 32$ & $371 \pm 32$ & $184 \pm 19$ & $1,599^{h} \pm 46$ & $1,029^{h} \pm 80$ & $1,003 \pm 54$ & $520 \pm 40$ & $2,352 \pm 40$ \\
\hline$\leq 200 \% \mathrm{FPL}$ & $1,522^{h} \pm 31$ & $218^{\mathrm{h}} \pm 19$ & $403 \pm 25$ & $172 \pm 18$ & $1,538^{h} \pm 30$ & $901 \pm 45$ & $989 \pm 40$ & $492 \pm 39$ & $2,316 \pm 36$ \\
\hline \multicolumn{10}{|c|}{ Vonparticipants in last 12 months } \\
\hline $130 \% \mathrm{FPL}$ & $1,567^{h} \pm 47$ & $231^{\mathrm{h}} \pm 36$ & $364 \pm 34$ & $189 \pm 22$ & $1,587^{h} \pm 44$ & $1,044^{h} \pm 88$ & $997 \pm 57$ & $521 \pm 42$ & $2,352 \pm 46$ \\
\hline$\leq 200 \% \mathrm{FPL}$ & $1,524^{h} \pm 30$ & $219^{h} \pm 19$ & $402 \pm 28$ & $172 \pm 19$ & $1,541^{\mathrm{h}} \pm \mathbf{2 8}$ & $913 \pm 50$ & $992 \pm 41$ & $484 \pm 41$ & $2,317 \pm 37$ \\
\hline
\end{tabular}

Nonparticipants in last 30 days, excluding occasional participants
$\leq 130 \% \mathrm{FPL}$
$\leq 200 \%$ FPL
$1,556^{\mathrm{h}} \pm \mathbf{4 8} \quad 233^{\mathrm{h}} \pm 34 \quad 360 \pm 36 \quad 194 \pm 22$
$1,575^{\mathrm{h}} \pm 44$
$1,059^{h} \pm 84$
$990 \pm 58 \quad 534 \pm 44$
$2,342 \pm 46$
$1,516^{\mathrm{h}}+31$
$221^{\mathrm{h}} \pm 19 \quad 396 \pm 30 \quad 179 \pm 20$
$1,532^{h} \pm 29$
$913 \pm 51 \quad 986 \pm 42 \quad 498 \pm 43$
$2,311 \pm 47$

Solid fats (\% total energy intake) ${ }^{i}$

SNAP participants in last 30 days

\begin{tabular}{|c|c|c|c|c|c|c|c|c|c|}
\hline$\leq 130 \% \mathrm{FPL}$ & $10.1 \pm 0.3$ & $0.5 \pm 0.1$ & $2.8 \pm 0.3$ & $1.3 \pm 0.2$ & $13.5 \pm 0.3$ & $14.5 \pm 1.1$ & $19.1 \pm 1.3$ & $14.9 \pm 1.2$ & $14.9 \pm 0.4$ \\
\hline$\leq 200 \% \mathrm{FPL}$ & $9.9 \pm 0.3$ & $0.5 \pm 0.1$ & $3.1 \pm 0.2$ & $1.3 \pm 0.2$ & $13.5 \pm 0.3$ & $14.1 \pm 1.1$ & $19.6 \pm 1.1$ & $15.6 \pm 1.3$ & $14.8 \pm 0.4$ \\
\hline \multicolumn{10}{|c|}{ NAP participants in last 12 months } \\
\hline$\leq 130 \% \mathrm{FPL}$ & $10.0 \pm 0.3$ & $0.5 \pm 0.1$ & $3.0 \pm 0.3$ & $1.2 \pm 0.2$ & $13.5 \pm 0.3$ & $14.1 \pm 1.1$ & $19.1 \pm 1.3$ & $14.2 \pm 1.2$ & $14.8 \pm 0.4$ \\
\hline$\leq 200 \% \mathrm{FPL}$ & $9.8 \pm 0.3$ & $0.6 \pm 0.1$ & $3.1 \pm 0.2$ & $1.2 \pm 0.2$ & $13.4 \pm 0.3$ & $13.8 \pm 1.1$ & $19.7 \pm 1.1$ & $15.1 \pm 1.3$ & $14.8 \pm 0.4$ \\
\hline
\end{tabular}


Table 5. Sensitivity analysis of daily nutrient consumption according to category of where food was purchased, by SNAP ${ }^{\mathrm{a}}$ participation, NHANES ${ }^{\mathrm{b}}$ 2011-2014 ${ }^{\mathrm{c}}$ (continued)

\begin{tabular}{|c|c|c|c|c|c|c|c|c|c|}
\hline \multirow[b]{2}{*}{ Food source } & \multicolumn{4}{|c|}{ Per-Capita Nutrient Consumption } & \multicolumn{4}{|c|}{ Per-Consumer Nutrient Consumption ${ }^{d}$} & \multirow[b]{2}{*}{$\begin{array}{l}\text { Total } \\
\text { consumption }\end{array}$} \\
\hline & Grocery store & $\begin{array}{l}\text { Sit-down } \\
\text { restaurant }\end{array}$ & Fast food & Other source & Grocery store & $\begin{array}{l}\text { Sit-down } \\
\text { restaurant }\end{array}$ & Fast food & Other source & \\
\hline \multicolumn{10}{|c|}{$\begin{array}{l}\text { SNAP participants in last } 30 \text { days, } \\
\text { excluding occasional participants }\end{array}$} \\
\hline$\leq 130 \% \mathrm{FPL}$ & $10.1 \pm 0.3$ & $0.5 \pm 0.1$ & $2.9 \pm 0.3$ & $1.3 \pm 0.2$ & $13.6 \pm 0.4$ & $14.4 \pm 1.1$ & $19.2 \pm 1.3$ & $14.9 \pm 1.3$ & $14.9 \pm 0.4$ \\
\hline$\leq 200 \% \mathrm{FPL}$ & $9.9 \pm 0.3$ & $0.5 \pm 0.1$ & $3.1 \pm 0.3$ & $1.3 \pm 0.2$ & $13.5 \pm 0.4$ & $14.2 \pm 1.1$ & $19.7 \pm 1.2$ & $15.7 \pm 1.3$ & $14.8 \pm 0.4$ \\
\hline \multicolumn{10}{|c|}{ Nonparticipants in last 30 days } \\
\hline$\leq 130 \% \mathrm{FPL}$ & $9.1^{\mathrm{h}} \pm 0.4$ & $1.3^{\mathrm{h}} \pm 0.2$ & $3.0 \pm 0.2$ & $1.3 \pm 0.2$ & $12.9 \pm 0.5$ & $13.8 \pm 0.9$ & $20.2 \pm 1.0$ & $14.1 \pm 1.1$ & $14.7 \pm 0.4$ \\
\hline$\leq 200 \% \mathrm{FPL}$ & $9.0^{\mathrm{h}} \pm 0.4$ & $1.3^{\mathrm{h}} \pm 0.1$ & $3.2 \pm 0.2$ & $1.1 \pm 0.2$ & $13.0 \pm 0.3$ & $12.8 \pm 0.9$ & $19.3 \pm 0.8$ & $13.6 \pm 1.2$ & $14.6 \pm 0.4$ \\
\hline \multicolumn{10}{|c|}{ Nonparticipants in last 12 months } \\
\hline$\leq 130 \% \mathrm{FPL}$ & $9.1 \pm 0.4$ & $1.4^{\mathrm{h}} \pm 0.2$ & $3.0 \pm 0.3$ & $1.4 \pm 0.2$ & $13.0 \pm 0.5$ & $14.0 \pm 0.9$ & $20.5 \pm 1.1$ & $14.6 \pm 1.0$ & $14.9 \pm 0.4$ \\
\hline$\leq 200 \% \mathrm{FPL}$ & $9.1 \pm 0.3$ & $1.3^{\mathrm{h}} \pm 0.1$ & $3.2 \pm 0.2$ & $1.1 \pm 0.2$ & $13.1 \pm 0.5$ & $12.7 \pm 1.2$ & $19.2 \pm 0.8$ & $13.8 \pm 1.2$ & $14.7 \pm 0.4$ \\
\hline \multicolumn{10}{|c|}{$\begin{array}{l}\text { Nonparticipants in last } 30 \text { days, } \\
\text { excluding occasional participants }\end{array}$} \\
\hline$\leq 130 \% \mathrm{FPL}$ & $9.0^{h} \pm 0.3$ & $1.4^{\mathrm{h}} \pm 0.2$ & $3.0 \pm 0.3$ & $1.4 \pm 0.2$ & $13.0 \pm 0.5$ & $13.8 \pm 0.9$ & $20.5 \pm 1.1$ & $14.6 \pm 1.1$ & $14.8 \pm 0.4$ \\
\hline$\leq 200 \% \mathrm{FPL}$ & $9.0^{h} \pm 0.3$ & $1.4^{\mathrm{h}} \pm 0.1$ & $3.2 \pm 0.2$ & $1.1 \pm 0.2$ & $13.1 \pm 0.5$ & $12.8 \pm 1.2$ & $19.3 \pm 0.8$ & $13.9 \pm 1.3$ & $14.7 \pm 0.4$ \\
\hline \multicolumn{10}{|c|}{ Added sugars (\% total energy intake) } \\
\hline \multicolumn{10}{|c|}{ SNAP participants in last 30 days } \\
\hline$\leq 130 \%$ FPL & $15.3 \pm 0.7$ & $0.3 \pm 0.1$ & $1.8 \pm 0.2$ & $1.4 \pm 0.2$ & $22.7 \pm 0.7$ & $13.9 \pm 1.3$ & $11.6 \pm 0.8$ & $22.6 \pm 2.6$ & $18.8 \pm 0.7$ \\
\hline$\leq 200 \% \mathrm{FPL}$ & $15.4 \pm 0.6$ & $0.4 \pm 0.1$ & $2.0 \pm 0.2$ & $1.4 \pm 0.2$ & $22.8 \pm 0.7$ & $13.5 \pm 1.1$ & $12.5 \pm 1.0$ & $23.2 \pm 2.5$ & $19.2 \pm 0.7$ \\
\hline \multicolumn{10}{|c|}{ SNAP participants in last 12 months } \\
\hline$\leq 130 \% \mathrm{FPL}$ & $15.1 \pm 0.6$ & $0.4 \pm 0.1$ & $1.9 \pm 0.2$ & $1.4 \pm 0.2$ & $22.5 \pm 0.7$ & $14.3 \pm 1.3$ & $12.3 \pm 0.8$ & $22.8 \pm 2.5$ & $18.8 \pm 0.7$ \\
\hline$\leq 200 \% \mathrm{FPL}$ & $15.2 \pm 0.6$ & $0.4 \pm 0.1$ & $2.1 \pm 0.2$ & $1.4 \pm 0.2$ & $22.7 \pm 0.7$ & $13.0 \pm 1.1$ & $13.2 \pm 1.0$ & $23.3 \pm 2.4$ & $19.1 \pm 0.7$ \\
\hline \multicolumn{10}{|c|}{$\begin{array}{l}\text { SNAP participants in last } 30 \text { days, } \\
\text { excluding occasional participants }\end{array}$} \\
\hline$\leq 130 \% \mathrm{FPL}$ & $15.2 \pm 0.7$ & $0.3 \pm 0.1$ & $1.9 \pm 0.2$ & $1.4 \pm 0.2$ & $22.5 \pm 0.7$ & $14.2 \pm 1.3$ & $11.9 \pm 0.8$ & $22.2 \pm 2.6$ & $18.7 \pm 0.7$ \\
\hline$\leq 200 \% \mathrm{FPL}$ & $15.3 \pm 0.6$ & $0.4 \pm 0.1$ & $2.0 \pm 0.2$ & $1.4 \pm 0.2$ & $22.6 \pm 0.7$ & $13.6 \pm 1.1$ & $12.7 \pm 1.0$ & $22.9 \pm 2.5$ & $19.1 \pm 0.7$ \\
\hline
\end{tabular}


Table 5. Sensitivity analysis of daily nutrient consumption according to category of where food was purchased, by SNAP participation, NHANES ${ }^{\mathrm{b}} 2011-2014^{c}$ (continued)

\begin{tabular}{|c|c|c|c|c|c|c|c|c|c|}
\hline \multirow[b]{2}{*}{ Food source } & \multicolumn{4}{|c|}{ Per-Capita Nutrient Consumption } & \multicolumn{4}{|c|}{ Per-Consumer Nutrient Consumption ${ }^{\mathrm{d}}$} & \multirow[b]{2}{*}{$\begin{array}{l}\text { Total } \\
\text { consumption }\end{array}$} \\
\hline & Grocery store & $\begin{array}{l}\text { Sit-down } \\
\text { restaurant }\end{array}$ & Fast food & Other source & Grocery store & $\begin{array}{l}\text { Sit-down } \\
\text { restaurant }\end{array}$ & Fast food & Other source & \\
\hline \multicolumn{10}{|c|}{ Nonparticipants in last 30 days } \\
\hline$\leq 130 \% \mathrm{FPL}$ & $11.8^{\mathrm{h}} \pm 0.6$ & $1.0 \pm 0.2$ & $1.8 \pm 0.2$ & $1.4 \pm 0.2$ & $19.5^{\mathrm{h}} \pm 0.6$ & $12.4 \pm 1.6$ & $13.3 \pm 1.1$ & $21.7 \pm 2.4$ & $16.1^{\mathrm{h}} \pm 0.7$ \\
\hline$\leq 200 \% \mathrm{FPL}$ & $11.3^{h} \pm 0.4$ & $1.0^{h} \pm 0.1$ & $2.0 \pm 0.2$ & $1.4 \pm 0.2$ & $19.0^{h} \pm 0.7$ & $11.8 \pm 1.2$ & $13.9 \pm 1.0$ & $22.8 \pm 1.9$ & $15.7^{h} \pm 0.5$ \\
\hline \multicolumn{10}{|c|}{ Nonparticipants in last 12 months } \\
\hline$\leq 130 \% \mathrm{FPL}$ & $11.5^{\mathrm{h}} \pm 0.6$ & $1.1^{\mathrm{h}} \pm 0.2$ & $1.7 \pm 0.2$ & $1.4 \pm 0.2$ & $19.3^{\mathrm{h}} \pm 1.0$ & $12.1 \pm 1.6$ & $12.6 \pm 1.1$ & $21.4 \pm 2.3$ & $15.7^{h} \pm 0.6$ \\
\hline$\leq 200 \% \mathrm{FPL}$ & $11.1^{h} \pm 0.4$ & $1.0^{h} \pm 0.1$ & $2.0 \pm 0.3$ & $1.4 \pm 0.2$ & $18.7^{h} \pm 0.8$ & $12.0 \pm 1.6$ & $13.3 \pm 1.0$ & $22.8 \pm 1.9$ & $15.5^{\mathrm{h}} \pm 0.5$ \\
\hline \multicolumn{10}{|c|}{$\begin{array}{l}\text { Nonparticipants in last } 30 \text { days, } \\
\text { excluding occasional participants }\end{array}$} \\
\hline$\leq 130 \% \mathrm{FPL}$ & $11.4^{h} \pm 0.5$ & $1.1^{\mathrm{h}} \pm 0.2$ & $1.7 \pm 0.2$ & $1.5 \pm 0.2$ & $19.1^{\mathrm{h}} \pm 0.9$ & $12.5 \pm 1.7$ & $13.1 \pm 1.1$ & $21.1 \pm 2.3$ & $15.7^{h} \pm 0.5$ \\
\hline$\leq 200 \% \mathrm{FPL}$ & $10.9^{h} \pm 0.4$ & $1.0^{h} \pm 0.1$ & $2.0 \pm 0.3$ & $1.4 \pm 0.2$ & $18.6^{\mathrm{h}} \pm 0.7$ & $12.1 \pm 1.2$ & $13.6 \pm 1.1$ & $22.5 \pm 1.8$ & $15.4^{h} \pm 0.4$ \\
\hline
\end{tabular}

${ }^{\mathrm{S}} \mathrm{SNAP}=$ Supplemental Nutrition Assistance Program.

bHANES = National Health and Nutrition Examination Survey.

'Data are for adults aged 20 to 64 years from NHANES 2011-2012 and 2013-2014. The sample size for SNAP participants, defined as receipt of benefits in the past 30 days, was 1,191 and 1,332 for income-eligible nonparticipants. Data are nationally representative, and results account for complex survey design. Each nutrient outcome was calculated for each category of food source and included in a separate linear regression model. All models were adjusted for year, age (age and age'), sex, marital status, employment, race/ethnicity (Mexican American, non-Hispanic white, non-Hispanic black [referent], other), income (poverty income ratio), education (<high school [referent], high school, some college, or college graduate or above), weekend consumption, and Special Supplemental Nutrition Program for Women, Infants and Children (WIC) participation.

In addition to restricting the sample to SNAP-eligible adults aged 20 to 64 with complete covariate and diet data, subpopulations are further restricted to those people who consumed calories from a given source. Therefore the subpopulation for "Grocery store" only includes those people who purchased at least one food item from a grocery store ( $n=1,162$ for SNAP participants) and is different from the subpopulation for "Restaurant" ( $\mathrm{n}=155$ for SNAP participants), although there is overlap between the two. For percent intakes, the calories from saturated fat and added sugar (SOFAS) are divided by the total number of calories consumed from that source to calculate the percentage of calories from a given source that are attributable to SOFAS

'Results in gray shading were presented in main analysis where SNAP participation was measured by receipt of benefits in the past 30 days and the sample was restricted to adults with a family income at or below $130 \%$ of the federal poverty level (FPL), the federal income eligibility criteria for SNAP. Three types of sensitivity analysis were conducted. First, because many states have expanded eligibility, the sample population was expanded to at or below 200\% FPL. Second, SNAP participation was defined as receipt of benefits within the past 12 months. Third, "occasional" participants were excluded from analysis to compare current SNAP participants with individuals who had not participated for at least a year. Results of sensitivity analysis are limited to calories, solid fats, and added sugars because very few differences were observed in servings of whole fruits, nonstarchy vegetables, and whole grains.

${ }^{\mathrm{F}}$ Comparisons are between participant and nonparticipant groups from the same sample population, defined by family income as a percentage of the FPL and SNAP status.

g"Occasional" participants are excluded from this analysis, or those individuals who were not currently receiving benefits but had received benefits in the past 12 months. This population of nonparticipants includes individuals who had not received benefits in at least 1 year and should be compared with SNAP participants who had received benefits in the past 30 days.

"Significant difference between SNAP participants and income-eligible nonparticipants at $P<0.025$. These results are also bolded.

'Dietary data for solid fats, added sugars, servings, and ounce equivalents are from the US Department of Agriculture Food Patterns Equivalents Database 2011-2012 and 2013-2014. Added sugars are those used as ingredients in processed and prepared foods and do not include naturally occurring sugars. Discretionary solid fats include fats from animal sources or hydrogenated vegetable oils. 
Table 6. Per-capita daily nutrient consumption according to category of where food was purchased, by SNAP ${ }^{\mathrm{a}}$ participation and time period, NHANES ${ }^{\mathrm{bc}}$

\begin{tabular}{|c|c|c|c|c|c|c|c|c|c|c|}
\hline \multirow[b]{2}{*}{ Food source } & \multicolumn{5}{|c|}{ 2003-2006 } & \multicolumn{5}{|c|}{ 2007-2010 } \\
\hline & Grocery store & $\begin{array}{l}\text { Sit-down } \\
\text { restaurant }\end{array}$ & Fast food & $\begin{array}{l}\text { Other } \\
\text { source }\end{array}$ & $\begin{array}{l}\text { Total } \\
\text { consumption }\end{array}$ & Grocery store & $\begin{array}{l}\text { Sit-down } \\
\text { restaurant }\end{array}$ & Fast food & $\begin{array}{l}\text { Other } \\
\text { source }\end{array}$ & $\begin{array}{l}\text { Total } \\
\text { consumption }\end{array}$ \\
\hline \multicolumn{11}{|l|}{ Calories } \\
\hline SNAP participants & $1,630 \pm 80$ & $95 \pm 31$ & $357 \pm 47$ & $103 \pm 31$ & $2,186 \pm 91$ & $1,690 \pm 49$ & $54 \pm 15$ & $329 \pm 26$ & $110 \pm 18$ & $2,182 \pm 42$ \\
\hline Nonparticipants & $1,753 \pm 51$ & $190^{\mathrm{d}} \pm 22$ & $362 \pm 39$ & $132 \pm 16$ & $2,437^{d} \pm 53$ & $1,593 \pm 43$ & $174^{d} \pm 25$ & $325 \pm 31$ & $127 \pm 19$ & $2,219 \pm 44$ \\
\hline \multicolumn{11}{|c|}{ Solid fats (\% total energy intake) ${ }^{e}$} \\
\hline SNAP participants & $12.7 \pm 0.9^{f}$ & $0.8 \pm 0.2$ & $3.6 \pm 0.5$ & $1.0 \pm 0.3$ & $18.1 \pm 0.1$ & $11.8 \pm 0.3$ & $0.4 \pm 0.1$ & $2.9 \pm 0.2$ & $0.7 \pm 0.2$ & $15.9 \pm 0.4$ \\
\hline Non-participants & $10.9 \pm 0.4^{c}$ & $1.3^{d} \pm 0.2$ & $3.5 \pm 0.3$ & $1.1 \pm 0.1$ & $18.9 \pm 0.1$ & $10.3^{d} \pm 0.4$ & $1.1^{\mathrm{d}} \pm 0.2$ & $2.9 \pm 0.2$ & $0.9 \pm 0.1$ & $15.3 \pm 0.4$ \\
\hline \multicolumn{11}{|c|}{ Added sugars (\% total energy intake) } \\
\hline SNAP participants & $16.6 \pm 1.0$ & $0.6 \pm 0.2$ & $1.9 \pm 0.3$ & $1.5 \pm 0.7$ & $21.0 \pm 1.0$ & $15.9 \pm 0.6$ & $0.4 \pm 0.1$ & $1.8 \pm 0.3$ & $1.0 \pm 0.2$ & $19.1 \pm 0.6$ \\
\hline Nonparticipants & $15.2 \pm 1.1$ & $1.2 \pm 0.2$ & $1.2 \pm 0.2$ & $1.2 \pm 0.2$ & $18.9^{\mathrm{d}} \pm 1.0$ & $13.0^{d} \pm 0.6$ & $0.8 \pm 0.2$ & $1.6 \pm 0.2$ & $1.3 \pm 0.1$ & $16.6^{\mathrm{d}} \pm 0.7$ \\
\hline \multicolumn{11}{|c|}{ Nonstarchy vegetables (servings) } \\
\hline SNAP participants & $0.6 \pm 0.1$ & $0.0 \pm 0.0$ & $0.2 \pm 0.0$ & $0.1 \pm 0.0$ & $0.9 \pm 0.1$ & $0.7 \pm 0.0$ & $0.0 \pm 0.0$ & $0.1 \pm 0.0$ & $0.1 \pm 0.0$ & $0.9 \pm 0.0$ \\
\hline Nonparticipants & $0.7 \pm 0.0$ & $0.1^{d} \pm 0.0$ & $0.2 \pm 0.0$ & $0.1 \pm 0.0$ & $1.1^{d} \pm 0.1$ & $0.7 \pm 0.0$ & $0.1^{d} \pm 0.0$ & $0.2 \pm 0.0$ & $0.1 \pm 0.0$ & $1.1 \pm 0.0$ \\
\hline \multicolumn{11}{|c|}{ Whole fruits (servings) } \\
\hline SNAP participants & $0.6 \pm 0.2$ & $0.0 \pm 0.0$ & $0.0 \pm 0.0$ & $0.1 \pm 0.0$ & $0.7 \pm 0.2$ & $0.4 \pm 0.1$ & $0.0 \pm 0.0$ & $0.0 \pm 0.0$ & $0.0 \pm 0.0$ & $0.4 \pm 0.1$ \\
\hline Nonparticipants & $0.6 \pm 0.1$ & $0.0 \pm 0.0$ & $0.0 \pm 0.0$ & $0.1 \pm 0.0$ & $0.7 \pm 0.1$ & $0.5 \pm 0.0$ & $0.0 \pm 0.0$ & $0.0 \pm 0.0$ & $0.0 \pm 0.0$ & $0.5 \pm 0.0$ \\
\hline \multicolumn{11}{|c|}{ Whole grains (ounce equivalents) } \\
\hline SNAP participants & $0.4 \pm 0.1$ & $0.0 \pm 0.0$ & $0.0 \pm 0.0$ & $0.0 \pm 0.0$ & $0.4 \pm 0.1$ & $0.4 \pm 0.1$ & $0.0 \pm 0.0$ & $0.0 \pm 0.0$ & $0.0 \pm 0.0$ & $0.5 \pm 0.1$ \\
\hline Nonparticipants & $0.5 \pm 0.1$ & $0.0 \pm 0.0$ & $0.0 \pm 0.0$ & $0.0 \pm 0.0$ & $0.5 \pm 0.1$ & $0.5 \pm 0.0$ & $0.0 \pm 0.0$ & $0.0 \pm 0.0$ & $0.0 \pm 0.0$ & $0.6 \pm 0.0$ \\
\hline
\end{tabular}

aSNAP=Supplemental Nutrition Assistance Program.

bNHANES=National Health and Nutrition Examination Survey.

'Data are for adults aged 20 to 64 years with an income at or below 130\% of the federal poverty level from NHANES 2003-2004, 2005-2006, 2007-2008, and 2009-2010. The sample size for SNAP participants was 373 in $2003-2006$ and 1,056 in 20072010. The sample size for income-eligible nonparticipants was 1,342 in 2003-2006 and 1,498 in 2007-2010. Data are nationally representative, and results account for complex survey design. Data samples were pooled, combining 2003-2004 with 2005-2006 and 2007-2008 with 2009-2010. Each nutrient outcome was calculated for each category of food source and included in a separate linear regression model. All models were adjusted for year, age (age and age 2), sex, marital status, employment, race/ethnicity (Mexican American, non-Hispanic white, non-Hispanic black [referent], other), income (poverty income ratio), education (<high school [referent], high school, some college, or college graduate or above), weekend consumption, and Special Supplemental Nutrition Program for Women, Infants and Children (WIC) participation.

${ }^{\mathrm{d}}$ Significant difference between SNAP participants and income-eligible nonparticipants within the same period, significant at $P<0.025$. These results are also bolded.

eDietary data for solid fats, added sugars, servings, and ounce equivalents are from US Department of Agriculture MyPlate Equivalents Database 2003-2004 and Food Patterns Equivalents Database 2005-2006, 2007-2008 and 2009-2010. Non starchy vegetables include dark green and orange vegetables, tomatoes, and other vegetables and exclude starchy vegetables, potatoes, and dry beans and peas. Added sugars are those used as ingredients in processed and prepared foods and do not include naturally occurring sugars. Discretionary solid fats include fats from animal sources or hydrogenated vegetable oils.

${ }^{f}$ Grayed Results in gray shading reflect models that failed an F-test of overall significance with a $P$ value $>0.05$. In other words, the model fails to fit the data better than simply using the intercept, or the mean nutrient intake from a given food source, to predict individual outcomes. 
results were unexpected; SNAP participants were anticipated to consume less fast food than nonparticipants because program benefits should make grocery store food relatively cheaper, therefore reducing fast-food consumption. The similar consumption of fast food suggests SNAP benefits are not sufficiently high to overcome the "cost" of preparing food at home. ${ }^{67}$ The time costs combined with the financial costs of $\mathrm{AH}$ food may make home food preparation relatively more expensive than fast-food consumption. The findings from this study support the Institute of Medicine's recommendations that SNAP benefits be increased to account for the time needed to prepare food at home. ${ }^{68}$ Although SNAP cannot affect the quality of fast-food, a sufficient increase in benefits may decrease the relative cost of $\mathrm{AH}$ food enough to reduce the consumption of fast food by SNAP participants compared with nonparticipants. Alternatively, SNAP-eligible foods could be expanded to include healthy, prepared foods, such as rotisserie chicken, which would reduce preparation time. ${ }^{69}$ This is an important area for potential future research, especially because fast-food consumption has been found to attenuate the association between home cooking and improved dietary quality among SNAP participants and nonparticipants. ${ }^{42}$ Interventions that increase benefits or expand SNAP-eligible purchases to include prepared foods could be accompanied by collection of time use and food diaries to evaluate how SNAP benefits and cooking time influence purchasing decisions and dietary quality.

The present study has several limitations. Because SNAP participation is voluntary and nonrandom, it is not possible to make any causal claims about the association between SNAP participation and the consumption of added sugar or healthy food. Eligibility varies by state, and individuals may not participate because of an application process that may be time consuming and, at times, demeaning. ${ }^{70}$ SNAP participants may also self-select into the program based on unobservable characteristics that are associated with poorer food selection. Future research is necessary to identify whether participation in SNAP is causally related to the dietary quality of food from different sources. Study findings are also limited by two types of misclassification error. First, self-reported dietary data are often misreported, because unhealthy foods are more likely to be underreported than healthy foods. ${ }^{71}$ Therefore, reported consumption of SoFAS may be lower than actual consumption, although differential misclassification between SNAP participants and nonparticipants is unlikely. Second, participants often report themselves to be nonparticipants. ${ }^{5,55,72,73}$ Mixing SNAP participants with nonparticipants would make the two groups more similar and attenuate observed differences.

Despite these limitations, this study has several strengths. In comparison with household purchase data, 24-hour dietary recall data capture foods consumed at an individual level rather than purchased at the household level. These data include food without barcodes, such as loose produce, and allow examination of food sources other than stores. Unlike purchase data, 24-hour recall data do not have to account for food waste or differential preferences within households. NHANES is also a nationally representative survey that oversamples populations with lower incomes, providing a large sample size with which to evaluate patterns in nutrient consumption in SNAP-eligible populations.

\section{PRACTICE IMPLICATIONS}

\section{What Is the Current Knowledge on this Topic?}

Supplemental Nutrition Assistance Program (SNAP) benefits can only be spent at authorized grocery stores, yet little is known about how this at-home food contributes to participants' dietary quality compared with awayfrom-home food.

\section{How Does this Research Add to Knowledge on this Topic?}

This is the first study to characterize nutrient intake according to where food is obtained by SNAP participants. Participants consume more solid fats and added sugars from grocery stores compared with low-income nonparticipants.

\section{How Might this Knowledge Affect Current Dietetics Practice?}

Consuming more at-home food was not associated with better diet quality for SNAP participants. Therefore interventions and dietary counseling should address healthful grocery store purchases.

\section{CONCLUSION}

The results of the present study show that SNAP participants consume more calories from AH foods, or grocery and convenience stores, than income-eligible nonparticipants. However, the higher consumption of $\mathrm{AH}$ food is not sufficient to improve the dietary quality of SNAP participants. This study indicates that the lower dietary quality of SNAP participants, as compared with nonparticipants, is attributable to the dietary quality of the AH food they consume, which is higher in added sugar and lower in nonstarchy vegetables. In comparison, nonparticipants consume more food and solid fats in sit-down restaurants. Both groups consume similar amounts of calories and SoFAS from fast-food establishments. Because SNAP benefits can only be redeemed at grocery stores, future research should evaluate the design, impact, and costeffectiveness of point-of-purchase interventions that incentivize the consumption of healthy AH food.

\section{References}

1. Levin SM, Barnard ND, Saltalamacchia RE. A proposal for improvements in the Supplemental Nutrition Assistance Program. Am J Prev Med. 2017;52(2S2):S186-S192.

2. Popkin BM. The challenge in improving the diets of Supplemental Nutrition Assistance Program Recipients: A historical commentary. Am J Prev Med. 2017;52(2S2):S106-S114.

3. Kelsey Farson Gray KC. Trends in Supplemental Nutrition Assistance Program Participation Rates: Fiscal Year 2010 to Fiscal Year 2015. U.S. Department of Agriculture, Food and Nutrition Service; June 2017. 
4. Condon E, Drilea S, Jowers K, et al. Diet Quality of Americans by SNAP Participation Status: Data from the National Health and Nutrition Examination Survey, 2007-2010. Mathematica Policy Research; 2015.

5. Fox MK, Hamilton W, Lin B-H. Effect of Food Assistance and Nutrition Programs on Nutrition and Health: Volume 3, Literature Review. Economic Research Service, U.S. Department of Agriculture; 2004.

6. Andreyeva T, Tripp AS, Schwartz MB. Dietary quality of Americans by Supplemental Nutrition Assistance Program participation status: A systematic review. Am J Prev Med. 2015;49(4):594-604.

7. Garasky S, Mbwana K, Romualdo A, Tenaglio A, Roy M. Foods Typically Purchased by SNAP Households. Alexandria, VA: Prepared by IMPAQ International, LLS for USDA, Food and Nutrition Service; November 2016.

8. Mancino L, Guthrie J, Ver Ploeg M, Lin B-H. Nutritional Quality of Foods Acquired by Americans: Findings from USDA's National Household Food Acquisition and Purchase Survey. Alexandria, VA: US Department of Agriculture, Economic Research Service. Economic Information Bulletin No. (EIB-188) February 2018. https://www.ers. usda.gov/publications/pub-details/?pubid=87530. Accessed March 7, 2018.

9. Nguyen BT, Powell LM. Supplemental Nutrition Assistance Program participation and sugar-sweetened beverage consumption, overall and by source. Prev Med. 2015;81:82-86.

10. Beatty TKM, Tuttle CJ. Expenditure response to increases in in-kind transfers: Evidence from the Supplemental Nutrition Assistance Program. Am J Agric Econ. 2014;97(2):390-404.

11. Jilcott SB, Liu H, DuBose KD, Chen S, Kranz S. Food Stamp participation is associated with fewer meals away from home, yet higher body mass index and waist circumference in a nationally representative sample. J Nutr Educ Behav. 2011;43(2): 110-115.

12. Pan S, Jensen HH. Does the Food Stamp program affect food security status and the composition of food expenditures? J Agric Appl Econ. 2008;40(1):21-35.

13. Mabli J, Malsberger R. Recent trends in spending patterns of Supplemental Nutrition Assistance Program participants and other lowincome Americans. Mon Labor Rev. 2013;136(9):1-32.

14. Ammerman AS, Hartman T, DeMarco MM. Behavioral economics and the Supplemental Nutrition Assistance Program. Am J Prev Med. 2017;52(2):S145-S150.

15. Gustafson AA, Allen I, James E IV, Schoenberg NE, Swanson M. The relationship between neighborhood food environment and food store choice on purchasing habits among SNAP and lower income households, USDA FoodAPS Data. 2016. University of Kentucky Center for Poverty Research Discussion Paper Series. 110. https://uknowledge. uky.edu/ukcpr_papers/110. Accessed March 21, 2018.

16. Guthrie J, Lin B, Frazao E. Role of food prepared away from home in the American diet, 1977-78 versus 1994-96: Changes and consequences. J Nutr Educ Behav. 2002;34(3):140-150.

17. Mancino L, Todd J, Lin B-H. Separating what we eat from where: Measuring the effect of food away from home on diet quality. Food Policy. 2009;34(6):557-562.

18. Poti JM, Popkin BM. Trends in energy intake among US children by eating location and food source, 1977-2006. I Am Diet Assoc. 2011;111(8):1156-1164.

19. Johnson CL, Dohrmann SM, Burt VL, Mohadjer LK. National Health and Nutrition Examination Survey: Sample design, 2011-2014. Vital Health Stat. 2014;2(162):1-33.

20. Supplemental Nutrition Assistance Program: Eligibility. U.S. Department of Agriculture, Food and Nutrition Services. https:// www.fns.usda.gov/snap/eligibility. Accessed July 2017.

21. Wilde PE. The new normal: The Supplemental Nutrition Assistance Program (SNAP). Am J Agric Econ. 2012;95(2):325-331.

22. Gregory C, Ploeg MV, Andrews A, Coleman-Jensen A. Supplemental Nutrition Assistance Program (SNAP) Participation Leads to Modest Changes in Diet Quality. U.S. Department of Agriculture, Economic Research Service; April 2013.

23. Gundersen C, Kreider B. Food stamps and food insecurity - What can be learned in the presence of nonclassical measurement error? J Hum Resour. 2008;43(2):352-382.

24. Todd JE, Ploeg MV. Caloric beverage intake among adult Supplemental Nutrition Assistance Program participants. Am J Public Health. 2014;104(9):e80-e85.
25. Centers for Disease Control and Prevention (CDC). National Center for Health Statistics (NCHS). National Health and Nutrition Examination Survey 2011-2012 (Food Security Questionnaire). Hyattsville, MD: U.S. Department of Health and Human Services, Centers for Disease Control and Prevention. https://wwwn.cdc.gov/Nchs/ Nhanes/2011-2012/FSQ_G.htm. Accessed January 2017.

26. Cole N, Fox M. Diet Quality of Americans by Food Stamp Participation Status: Data from the National Health and Nutrition Examination Survey. Alexandria, VA: US Department of Agriculture, Food and Nutrition Service, Office of Research, Nutrition and Analysis; 2008.

27. Nguyen BT, Shuval K, Njike VY, Katz DL. The Supplemental Nutrition Assistance Program and dietary quality among US adults: Findings from a nationally representative survey. Paper presented at: Mayo Clinic Proceedings 2014.

28. Leung CW, Ding EL, Catalano PJ, Villamor E, Rimm EB, Willett WC Dietary intake and dietary quality of low-income adults in the Supplemental Nutrition Assistance Program. Am J Clin Nutr. 2012;96(5):977-988.

29. Centers for Disease Control and Prevention (CDC). National Center for Health Statistics (NCHS). National Health and Nutrition Examination Survey MEC In-Person Dietary Interviewers Procedure Manual. Hyattsville, MD: U.S. Department of Health and Human Services, Centers for Disease Control and Prevention; 2014.

30. Centers for Disease Control and Prevention (CDC). National Center for Health Statistics (NCHS). National Health and Nutrition Examination Survey 2013-2014 (Dietary Intervew - Individual Foods, First Day). Hyattsville, MD: US Department of Health and Human Services, Centers for Disease Control and Prevention. https://wwwn.cdc.gov/ nchs/nhanes/2013-2014/DR1IFF_H.htm. Accessed January 2017.

31. Dodd KW, Guenther PM, Freedman LS, et al. Statistical methods for estimating usual intake of nutrients and foods: A review of the theory. J Am Diet Assoc. 2006;106(10):1640-1650.

32. Overview of the Food and Nutrient Database for Dietary Studies. U.S Department of Agriculture, Agriculture Research Service. https://www ars.usda.gov/northeast-area/beltsville-md-bhnrc/beltsville-humannutrition-research-center/food-surveys-research-group/docs/fndds/. Accessed July 7, 2017.

33. Overview of Food Patterns Equivalents Database. U.S. Department of Agriculture, Agriculture Research Service. https://www.ars.usda.gov/ northeast-area/beltsville-md-bhnrc/beltsville-human-nutrition-researchcenter/food-surveys-research-group/docs/fped-overview/. Accessed July 7, 2017.

34. US Department of Health and Human Services and US Department of Agriculture. 2015-2020 Dietary Guidelines for Americans. 8th ed. December 2015. https://health.gov/dietaryguidelines/2015/guidelines/. Accessed March 13, 2018.

35. Centers for Disease Control and Prevention (CDC). National Center for Health Statistics (NCHS). National Health and Nutrition Examination Survey 2011-2012 (Demographics). Hyattsville, MD: U.S. Department of Health and Human Services, Centers for Disease Control and Prevention. https://wwwn.cdc.gov/Nchs/Nhanes/2011 2012/DEMO_G.htm. Accessed January 2017.

36. Centers for Disease Control and Prevention (CDC). National Center for Health Statistics (NCHS). National Health and Nutrition Examination Survey 2013-2014 (Demographics). Hyattsville, MD: U.S. Department of Health and Human Services, Centers for Disease Control and Prevention. https://wwwn.cdc.gov/Nchs/Nhanes/2013-2 014/DEMO_H.htm. Accessed January 2017.

37. Centers for Disease Control and Prevention (CDC). National Center for Health Statistics (NCHS). National Health and Nutrition Examination Survey 2013-2014 (Food Security Questionnaire). Hyattsville, MD: U.S. Department of Health and Human Services, Centers for Disease Control and Prevention. https://wwwn.cdc.gov/Nchs/ Nhanes/2013-2014/FSQ_H.htm. Accessed January 2017.

38. Centers for Disease Control and Prevention (CDC). National Center for Health Statistics (NCHS). National Health and Nutrition Examination Survey 2011-2012 (Occupation Questionnaire). Hyattsville, MD: U.S. Department of Health and Human Services, Centers for Disease Control and Prevention. https://wwwn.cdc.gov/Nchs/ Nhanes/2011-2012/OCQ_G.htm. Accessed January 2017.

39. Centers for Disease Control and Prevention (CDC). National Center for Health Statistics (NCHS). National Health and Nutrition Examination Survey 2013-2014 (Occupation Questionnaire). Hyattsville, MD: U.S. Department of Health and Human Services, Centers for Disease Control and Prevention. https://wwwn.cdc.gov/Nchs/ Nhanes/2013-2014/OCQ H.htm. Accessed January 2017. 
40. Johnson CL, Paulose-Ram R, Ogden CL, et al. National health and nutrition examination survey: Analytic guidelines, 1999-2010. Vital Health Stat 2. 2013 Sep;(161):1-24.

41. Bleich SN, Vine S, Wolfson JA. American adults eligible for the Sup plemental Nutritional Assistance Program consume more sugary beverages than ineligible adults. Prev Med. 2013;57(6):894-899.

42. Taillie LS, Poti JM. Associations of cooking with dietary intake and obesity among Supplemental Nutrition Assistance Program participants. Am J Prev Med. 2017;52(2):S151-S160.

43. StataCorp. Stata Statistical Software. Release 14. College Station, TX: StataCorp LP; 2015.

44. Cutin LR, Mohadjer LK, Dohrmann SM, et al. The National Health and Nutrition Examination Survey: Sample Design 1999-2006. National Center for Health Statistics; 2012.

45. Drewnowski A, Rehm CD. Consumption of added sugars among US children and adults by food purchase location and food source. Am J Clin Nutr. 2014;100(3):901-907.

46. Grummon AH, Taillie LS. Nutritional profile of Supplemental Nutrition Assistance Program household food and beverage purchases. Am J Clin Nutr. 2017;105(6):1433-1442.

47. Andreyeva T, Luedicke J, Henderson KE, Tripp AS. Grocery store beverage choices by participants in federal food assistance and nutrition programs. Am J Prev Med. 2012;43(4):411-418.

48. Park J, Lin H-C, Peng C-Y. The Supplemental Nutrition Assistance Program and frequency of sugar-sweetened soft drink consumption among low-income adults in the US. Nutr Health. 2017;23(3):147-157.

49. Laraia BA, Leak TM, Tester JM, Leung CW. Biobehavioral factors that shape nutrition in low-income populations: A narrative review. Am J Prev Med. 2017;52(2S2):S118-S126.

50. Hillier A, Chrisinger B, Smith TE, Whiteman E, Kallan M. Influence of SNAP participation and food environment on nutritional quality of food at home purchases. University of Kentucky Center for Poverty Research Discussion Paper Series; 2016. https://uknowledge.uky.edu/ ukcpr_papers/111/. Accessed May 5, 2018.

51. Lin B-H, Guthrie J. Nutritional quality of food prepared at home and away from home. Washington, DC: Economic Research Service, US Department of Agriculture; 2012. b-details/?pubid=43699. Accessed March 20, 2018.

52. Leung CW, Musicus AA, Willett WC, Rimm EB. Improving the nutritional impact of the Supplemental Nutrition Assistance Program: Perspectives from the participants. Am J Prev Med. 2017;52(2S2):S193-S198.

53. Mancino L, Guthrie J. SNAP households must balance multiple priorities to achieve a healthful diet. Amber Waves. Nov 3, 2014. https://www. ers.usda.gov/amber-waves/2014/november/snap-households-mustbalance-multiple-priorities-to-achieve-a-healthful-diet/. Accessed March 21, 2018.

54. Rydell SA, Turner RM, Lasswell TA, et al. Participant satisfaction with a food benefit program with restrictions and incentives. J Acad Nutr Diet. 2018;118(2):294-300.

55. Dannefer R, Abrami A, Rapoport R, Sriphanlop P, Sacks R, Johns M. A mixedmethods evaluation of a SNAP-Ed farmers' market-based nutrition education program. J Nutr Educ Behav. 2015;47(6): 516-525.e511.

56. Just DR, Gabrielyan G. Influencing the food choices of SNAP consumers: Lessons from economics, psychology and marketing [published online ahead of print March 15, 2018]. Food Policy. 2018. https://doi.org/10.1016/j.foodpol.2018.03.003.
57. Bleich S, Rimm E, Brownell K. U.S. Nutrition Assistance, 2018 Modifying SNAP to Promote Population Health. $N$ Engl J Med. 2017;376(13):1205-1207.

58. Klerman JA, Collins AM, Olsho LE. Improving nutrition by limiting choice in the Supplemental Nutrition Assistance Program. Am J Prev Med. 2017;52(2):S171-S178.

59. Olsho LE, Klerman JA, Wilde PE, Bartlett S. Financial incentives increase fruit and vegetable intake among Supplemental Nutrition Assistance Program participants: A randomized controlled trial of the USDA Healthy Incentives Pilot-3. Am J Clin Nutr. 2016;104(2): 423-435.

60. An R. Nationwide expansion of a financial incentive program on fruit and vegetable purchases among Supplemental Nutrition Assistance Program participants: A cost-effectiveness analysis. Soc Sci Med. 2015; $147: 80-88$.

61. Choi SE, Seligman H, Basu S. Cost effectiveness of subsidizing fruit and vegetable purchases through the supplemental nutrition assistance program. Am J Prev Med. 2017;52(5):e147-e155.

62. Cuffey J, Beatty TK, Harnack L. The potential impact of Supplemental Nutrition Assistance Program (SNAP) restrictions on expenditures: A systematic review. Public Health Nutr. 2016;19(17):3216-3231.

63. French SA, Rydell SA, Mitchell NR, Michael Oakes J, Elbel B, Harnack L. Financial incentives and purchase restrictions in a food benefit program affect the types of foods and beverages purchased: Results from a randomized trial. Int J Behav Nutr Phys Act. 2017;14(1):127.

64. Harnack L, Oakes J, Elbel B, Beatty T, Rydell S, French S. Effects of subsidies and prohibitions on nutrition in a food benefit program: A randomized clinical trial. JAMA Intern Med. 2016;176(11):1610-1619.

65. Tiehen L, Newman C, Kirlin JA. The Food-spending Patterns of Households Participating in the Supplemental Nutrition Assistance Program: Findings from USDA's FoodAPS. Alexandria, VA: United States Department of Agriculture, Economic Research Service; 2017.

66. Poti JM, Duffey KJ, Popkin BM. The association of fast food consumption with poor dietary outcomes and obesity among children: Is it the fast food or the remainder of the diet? Am J Clin Nutr. 2014;99(1):162-171.

67. Davis GC. Food at home production and consumption: Implications for nutrition quality and policy. Rev Econ Househ. 2014;12(3):565-588.

68. Council). IIoMaNNR. Supplemental Nutrition Assistance Program: Examining the Evidence to Define Benefit Adequacy. Washington, DC: National Academies Press; 2013.

69. Yaktine AL, Caswell JA. SNAP benefits: Can an adequate benefit be defined? Adv Nutr. 2014;5(1):21-26.

70. Burstein NR, Patrabansh S, Hamilton WL, Siegel SY. Understanding the Determinants of Supplemental Nutrition Assistance Program Participation. Alexandria, VA: U.S. Department of Agriculture, Food and Nutrition Service, Office of Research and Analysis; 2009.

71. Rasmussen LB, Matthiessen J, Biltoft-Jensen A, Tetens I. Characteristics of misreporters of dietary intake and physical activity. Public Health Nutr. 2007;10(3):230-237.

72. Almada L, McCarthy I, Tchernis R. What can we learn about the effects of Food Stamps on obesity in the presence of misreporting? Am J Agric Econ. 2016;98(4):997-1017.

73. Meyer BD, George R. Errors in Survey Reporting and Imputation and Their Effects on Estimates of Food Stamp Program Participation. U.S. Census Bureau, Center for Economic Studies; 2011. Paper No. CESWP-11-14. 


\section{AUTHOR INFORMATION}

A. M. Lacko is a doctoral student and L. Smith Taillie is a research assistant professor, Department of Nutrition and Carolina Population Center, University of North Carolina at Chapel Hill. B. M. Popkin is the W. R. Kenan, Jr Distinguished Professor, Department of Nutrition and Carolina Population Center, Gillings School of Global Public Health, University of North Carolina at Chapel Hill.

Address correspondence to: Lindsey Smith Taillie, PhD, Carolina Square, 123 W Franklin St, Building C, Suite 210, Chapel Hill, NC 27516. E-mail: taillie@unc.edu

\section{STATEMENT OF POTENTIAL CONFLICT OF INTEREST}

No potential conflict of interest was reported by the authors.

\section{FUNDING/SUPPORT}

National Institutes of Health (NIH) (R01DK098072; DK056350) and the Carolina Population Center (NIH P2C HD050924).

\section{DATA STATEMENT}

This study included data from the National Health and Nutrition Examination Survey (NHANES), a cross-sectional, nationally representative survey of the US population. Dietary, demographic and questionnaire data were used from the 2011-2012 and 2013-2014 waves of NHANES (supplemental analysis also used data from the 2003-2004, 2005-2006, 2007-2008 and 2009-2010 waves).

Dietary data for solid fats, added sugars, servings and ounce equivalents are from the USDA MyPlate Equivalents Database 2003-2004 and Food Patterns Equivalents Database 2005-2006, 2007-2008, 2009-2010, 2011-2012 and 2013-2014. Non-starchy vegetables include dark-green and orange vegetables, tomatoes and other vegetables, and exclude starchy vegetables, potatoes and dry beans and peas. Added sugars are those used as ingredients in processed and prepared foods and do not include naturally occurring sugars. Discretionary solid fats include fats from animal sources or hydrogenated vegetable oils.

All data are publicly available.

\section{ACKNOWLEDGEMENTS}

We wish to thank Phil Bardsley, PhD, for exceptional assistance with the data management; Frances Dancy Burton for administrative assistance: and Denise Ammons for graphics support.

\section{AUTHOR CONTRIBUTIONS}

A. M. Lacko, B. M. Popkin, and L. Smith Taillie participated in the design of the study; A. M. Lacko collected the data and conducted primary analysis; all authors reviewed and refined analysis; A. M. Lacko wrote the first draft; all authors reviewed and commented on subsequent drafts of the manuscript. 